http://jmscr.igmpublication.org/home/

ISSN (e)-2347-176x ISSN (p) 2455-0450

crossref DOI: https://dx.doi.org/10.18535/jmscr/v9i2.25

Journal Of Medical Science And Clinical Research

IGM Publication

An Official Publication of IGM Publication

\title{
Management of Laparostomy Wound: A Complex Surgical Problem - A Case Report
}

\author{
Authors \\ Ajay.P. ${ }^{1}$, Chetan Anand ${ }^{2}$, Dinker Pai ${ }^{3}$ \\ ${ }^{1}$ Senior Resident (General Surgery), Mahatma Gandhi Medical College, Pondicherry \\ ${ }^{2}$ Assistant Prof (General Surgery), Mahatma Gandhi Medical College, Pondicherry \\ ${ }^{3}$ Prof (General Surgery), Mahatma Gandhi Medical College, Pondicherry
}

\begin{abstract}
Introduction: Open abdomen is a strategy used to avoid abdominal compartment syndrome, and management of open abdominal wounds have a vital role.

Case Report: 38 year old male came with history of blunt abdominal trauma 3 days prior. He was taken up for emergency laparotomy following CT abdomen. Intra operatively, left ischemic colonic segment resection was done followed by double barrel colostomy. Because of bowel edema the wound was managed as a laparostomy.

Conclusion: There are different ways to manage a laparostomy wound and here we have applied negative pressure to manage the wound with success.

Keywords: Difficulty in abdominal closure, Negative VAC therapy, different types of abdominal closure.
\end{abstract}

\section{Introduction}

In 1997 the first vacuum assisted closure was reported. ${ }^{1,2}$ It helps in secondary wound healing. It is the most common treatment for complex wound closure. A non adhesive foam with multiple pores dressing placed into the wound cavity and with controlled negative pressure will inhibit bacterial colonization, and reduce tissue oedema. VAC promotes good wound granulation. ${ }^{2,3} \mathrm{VAC}$ has been recently used in other fields as gastrointestinal surgery, plastic surgery for open abdominal wounds. ${ }^{4,5,6}$ the time for reconstruction is shorten. However there are many reports which state the use of VAC for open abdominal wounds with enterocutaneous fistula, wound dehiscence and surgical site infection. ${ }^{7,8}$

\section{Case Presentation}

38-year-old male sustaining a blunt left thoracoabdominal trauma two days earlier and having been managed at GH for two days. He was admitted under General surgery with a working diagnosis of blunt thoracoabdominal trauma. An emergency plain CT abdomen and thorax was done in view of elevated renal functions. CT report showed air pockets in the descending colon and clinically the patient deteriorated so underwent an emergency exploratory laparotomy wherein faecal peritoneal fluid with unhealthy left colon was noted. Excision of this colonic segment and double barrel colostomy was done. Abdomen could not be closed due to severe bowel oedema. Relook procedure done on day 2 showed no evidence of nonviable bowel segments. Abdomen 
could not be closed due to continuing bowel oedema and it was therefore planned to be managed a s a laparostomy wound. Patient received total parenteral nutrition and required a tracheostomy for prolonged ventilatory support. With a view to achieve temporary abdominal closure and to stabilize and control intraabdominal sepsis patient's complex abdominal wound was managed with (open abdomen closure with VAC dressing). Patient responded well to the ICU and surgical management strategies and was planned for split skin graft after healthy granulation.

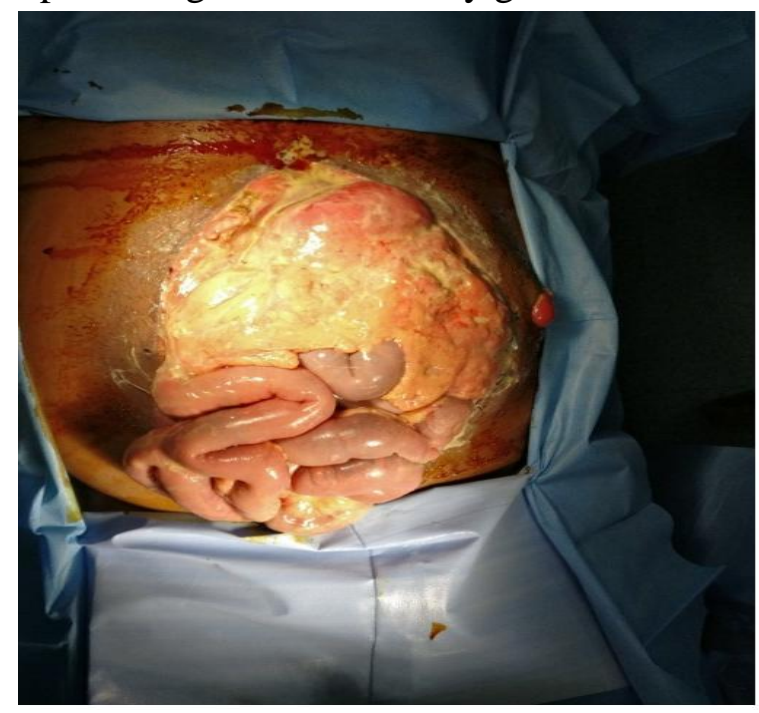

Initial wound vac dressing

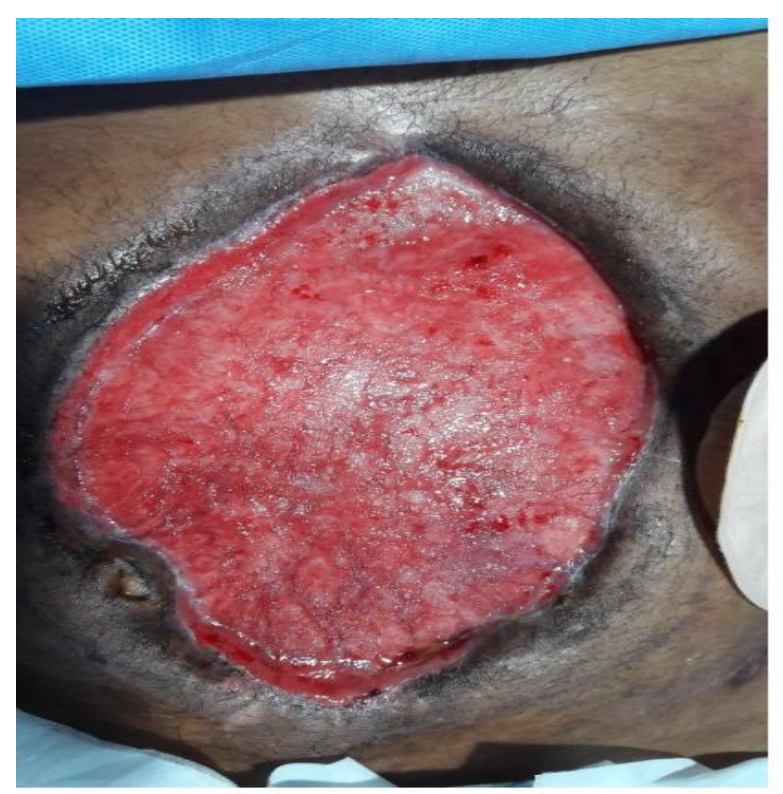

Granulation after split skin graft

\section{Discussion}

Open abdomen is a strategy used to avoid abdominal compartment syndrome. It has become a significant intermediate step in the treatment of abdominal emergencies especially in unstable patients. It has proven effective in reducing mortality postoperative complication. Subsequent wound management and closure remains a challenging surgical problem.

This case presented following blunt trauma to the abdomen that was difficult to close due to bowel oedema. The aim was to prevent a prolonged open wound. Many options including baggottabag, primary closure of fascia, component separation and mesh repair were considered, but each had its own disadvantages.

Primary abdominal closure can be achieved in patients with blunt abdominal trauma but when closure is not possible with the use of component separation, insertion of pre-peritoneal biological mesh, where negative VAC therapy can be applied for better results and fast outcome.

\section{Conclusion}

Laparostomy wound closure is a difficult surgical problem. Many methods are described for closure, but each has its own advantages and disadvantages. Vacuum assisted closure is convenient, feasible and without further morbidity. The overall results of vacuum assisted closure are very good.

\section{Reference}

1. L.C. Argenta, M.J. Morykwas Vacuumassisted closure: a new method for wound control and treatment: clinical experience Ann. Plast. Surg, 38 (1997), pp. 563-577

2. M.J. Morykwas, L.C. Argenta, E.I. Shelton -Brown, W. McGuirtVacuum-assisted closure: a new method for wound control and treatment: animal studies and basic foundation Ann. Plast. Surg., 38 (1997), pp. 553-562

3. V. Saxena, C.W. Hwang, S. Huang, Q. Eic hbaum, D. Ingber, D.P. OrgillVacuum- 
assisted closure: microdeformations of wounds and cell proliferation Plast. Reconstr. Surg., 114 (2004), pp. 10861096.

4. A.J. DeFranzo, K. Pitzer, J.A. Molnar, M. W. Marks, M.C. Chang, P.R. Miller, et al. Vacuum-assisted closure for defects of the abdominal wall Plast. Reconstr. Surg., 121 (2008), pp. 832-839

5. C.C. Cothren, E.E. Moore, J.L. Johnson, J. B. Moore, J.M. BurchOne hundred percent fascial approximation with sequential abdominal closure of the open abdomen Am. J. Surg., 192 (2006), pp. 238-242

6. S. Fujino, N. Miyoshi, M. Ohue, S. Noura, Y. Fujiwara, M. Yano, et al. Vacuumassisted closure for open perineal wound after abdominoperineal resection Int. J. Surg. Case Rep., 11 (2015), pp. 87-90

7. J. Goverman, J.A. Yelon, J.J. Platz, R.C. S ingson, M. TurcinovicThe Fistula VAC: a technique for management of enterocutaneous fistulae arising within the open abdomen: report of 5 cases $\mathrm{J}$. Trauma, 60 (2006), pp. 428-431

8. K. Boulanger, V. Lemaire, D. JacqueminV acuum-assisted closure of enterocutaneous fistula Acta Chir. Belg., 107 (2007), pp. 703-705. 